\title{
Cognitive predictors of reactive and proactive aggression in a forensic sample
}

Citation for published version (APA):

Brugman, S., Lobbestael, J., Sack, A. T., Cima, M. J., Schuhmann, T., Emmerling, F., \& Arntz, A. (2018). Cognitive predictors of reactive and proactive aggression in a forensic sample: A comparison with a nonclinical sample. Psychiatry Research, 269, 610-620. https://doi.org/10.1016/j.psychres.2018.08.095

Document status and date:

Published: 01/11/2018

DOI:

10.1016/j.psychres.2018.08.095

Document Version:

Publisher's PDF, also known as Version of record

Document license:

Taverne

Please check the document version of this publication:

- A submitted manuscript is the version of the article upon submission and before peer-review. There can be important differences between the submitted version and the official published version of record.

People interested in the research are advised to contact the author for the final version of the publication, or visit the DOI to the publisher's website.

- The final author version and the galley proof are versions of the publication after peer review.

- The final published version features the final layout of the paper including the volume, issue and page numbers.

Link to publication

\footnotetext{
General rights rights.

- You may freely distribute the URL identifying the publication in the public portal. please follow below link for the End User Agreement:

www.umlib.nl/taverne-license

Take down policy

If you believe that this document breaches copyright please contact us at:

repository@maastrichtuniversity.nl

providing details and we will investigate your claim.
}

Copyright and moral rights for the publications made accessible in the public portal are retained by the authors and/or other copyright owners and it is a condition of accessing publications that users recognise and abide by the legal requirements associated with these

- Users may download and print one copy of any publication from the public portal for the purpose of private study or research.

- You may not further distribute the material or use it for any profit-making activity or commercial gain

If the publication is distributed under the terms of Article $25 \mathrm{fa}$ of the Dutch Copyright Act, indicated by the "Taverne" license above, 


\title{
Cognitive predictors of reactive and proactive aggression in a forensic sample: A comparison with a non-clinical sample
}

\author{
Suzanne Brugman ${ }^{\mathrm{a}, \mathrm{b}, *}$, Jill Lobbestael ${ }^{\mathrm{a}}$, Alexander T. Sack ${ }^{\mathrm{c}, \mathrm{d}}$, Maaike J. Cima ${ }^{\mathrm{e}, \mathrm{f}}$, \\ Teresa Schuhmann ${ }^{\mathrm{c}, \mathrm{d}}$, Franziska Emmerling ${ }^{\mathrm{c}, \mathrm{d}, \mathrm{h}}$, Arnoud Arntz ${ }^{\mathrm{a}, \mathrm{g}}$ \\ a Department of Clinical Psychological Science (CPS), Faculty of Psychology and Neuroscience (FPN), Maastricht University, Universiteitssingel 40, P.O. Box 616, 6200 \\ MD Maastricht, The Netherlands. \\ ${ }^{\mathrm{b}}$ Forensic Psychiatric Centre Pompestichting, Nijmegen, The Netherlands \\ ${ }^{\mathrm{c}}$ Department of Cognitive Neuroscience, Faculty of Psychology and Neuroscience, Maastricht University, The Netherlands \\ ${ }^{\mathrm{d}}$ Maastricht Brain Imaging Center, The Netherlands \\ e Department of Developmental Psychopathology, Behavioral Science Institute, Radboud University, Nijmegen, The Netherlands \\ ${ }^{\mathrm{f}}$ Stichting CONRISQ group, Zetten, The Netherlands \\ ${ }^{g}$ Department of Clinical Psychology, Department of Faculty of Social and Behavioural Sciences, University of Amsterdam, The Netherlands \\ ${ }^{\mathbf{h}}$ Technical University of Munich, Germany
}

\section{A R T I C L E I N F O}

\section{Keywords:}

Cognitive predictors

Aggressive behavior

Taylor aggression paradigm

Reactive aggression

Proactive aggression

Forensic psychiatric patients

\begin{abstract}
A B S T R A C T
This study aimed at examining cognitive predictors of reactive and proactive aggression in a forensic-psychiatric $(n=80)$ and a non-clinical sample ( $n=98$; Brugman et al., 2015). Three different cognitive predictors were incorporated: (1) attentional bias towards aggressive stimuli (measured with Emotional Stroop task) and towards angry faces (measured with a visual search task); (2) interpretation biases (measured with Aggressive Interpretative Bias Task (AIBT) and a vignette task), and (3) implicit self-aggression association (measured with a Single-Target Implicit Association Task). To measure aggression, the Reactive-Proactive Aggression Questionnaire (RPQ) and the Taylor Aggression Paradigm (TAP) were used. An automatic self-aggression association positively predicted proactive aggressive behavior on the TAP in both samples. Furthermore, this selfaggression association predicted, increased self-reported proactive aggression (RPQ) in the forensic sample only. Pain, injury, and danger interpretations reported on the vignettes, negatively predicted self-reported proactive aggression in both samples. A stronger aggressive interpretation bias on the AIBT predicted more reactive aggressive behavior (TAP) in the non-clinical sample only. Taken together, findings show both common and distinct mechanisms in reactively vs. proactively driven aggressive behavior.
\end{abstract}

\section{Introduction}

Aggressive behavior, or any behavior intentionally carried out to cause harm to another person (e.g. Anderson and Bushman, 2002), is often divided into two motivational subtypes: reactive aggression -defined as hostile, impulsive, driven by anger, often occurring in reaction to a (perceived) provocation or frustration - and proactive aggression instrumental behavior, that is planned and used to obtain a goal (Anderson and Bushman, 2002). A number of studies have shown that reactive and proactive aggression each relate to different antecedents and outcomes (for an overview, see Cima and Raine, 2009).

Several theoretical models on the role of cognitive factors in aggressive behavior (e.g. Anderson and Bushman, 2002; Strack and
Deutsch, 2004) have been proposed. One of these models is the Social Information Processing Model (SIP; Crick and Dodge, 1994), which specifies six steps: (1) encoding of social cues, (2) interpretation of these cues, (3) goal selection, (4) response access based upon memory, (5) response decision, and (6) behavioral enactment. According to the model, a distortion or so-called bias in one or more of the steps can lead to aggressive behavior. This study aims to test whether these distortions or biases are predictive of aggressive behavior. Selection of the cognitive factors and tests to measure these factors is based upon the SIPmodel.

The first step of the SIP-model, the encoding phase, has been the focus of several studies. A relation was found between attentional interference of violence-related or negative stimuli and aggressive

\footnotetext{
*Corresponding author at: Department of Clinical Psychological Science (CPS), Faculty of Psychology and Neuroscience (FPN), Maastricht University, Universiteitssingel 40, P.O. Box 616, 6200 MD Maastricht, The Netherlands.

E-mail address: suzanne.brugman@maastrichtuniversity.nl (S. Brugman).
} 
behavior (e.g. Cohen et al., 1998; Honk et al., 2001; Kirsh et al., 2005; Stewart et al., 2010) and attentional interference further predicted aggressive behavior in forensic in-patients, suggesting it to be a marker of a causal process (Brugman et al., 2015; Brugman et al., 2016).

The second step of the SIP-model, cue interpretation, has been extensively studied, especially in children. De Castro et al. (2002) established a robust relation between a hostile interpretation bias and aggressive behavior in children in their meta-analysis. In an adult sample, an aggressive interpretation bias was found to be positively related to reactive aggression (Lobbestael et al., 2013).

Next to aggressive attention and interpretation bias, the current article further focuses on automatic self-aggression associations, which assumably relates to the fourth step of the SIP-model (response access). A stronger self-aggression association could be linked to the aggressive response repertoire in the long-term memory (Crick and Dodge, 1996). Grumm et al., (2011) showed that implicit self-aggression associations in children predicted their aggressive behavior in a computer game. In the study of Banse et al., (2015) it was shown that an automatic selfaggression association predicted both laboratory aggression and the number of penalties obtained by ice hockey players (i.e. 'natural' aggression).

Two previous studies of our group (Brugman et al., 2015; Brugman et al., submitted) tested whether attentional and interpretational biases, and self-aggression associations predicted behavioral and self-reported reactive and proactive aggression in a non-clinical sample. It was found that heightened attentional interference for aggressive stimuli predicted more reactive, while lower attentional interference predicted more proactive aggressive behavior (Brugman et al., 2015). Furthermore, using an open-ended ambiguous vignette task, the feeling of being excluded by others was shown to relate to more self-reported reactive aggression. On the other hand, blaming others to be the cause of a problem and reporting less doubt while judging the ambiguous situations was related to more self-reported proactive aggression (Brugman et al., submitted). A stronger implicit self-aggression association predicted more proactive aggressive behavior (Brugman et al., 2015).

These and other (e.g. Banse et al., 2015; Grumm et al., 2011) results give a first insight into the predictive value of cognitive processes underlying reactive and proactive aggression. Because all these studies relied on non-clinical samples the question remains, whether these results are generalizable to a clinical sample. Brugman et al., (2016) already showed that there are meaningful cognitive predictors of aggressive in-clinic incidents, but importantly, were not able to differentiate between reactive versus proactive motivation for these incidents. It would be particularly valuable to test whether the cognitive factors display the same predictive value for reactive and proactive aggression in non-clinical and forensic samples.

Therefore, the goal of the current study was to examine the predictive value an attentional bias, interpretation bias, and an automatic self-aggression association for reactive and proactive aggression in a forensic sample. These values were then directly compared with those found in a non-clinical sample (Brugman et al., 2015; Brugman et al., submitted). As earlier studies showed discrepant findings regarding the relation between the described cognitive factors and reactive and proactive aggression, it was decided to base our hypotheses on the general premises of the SIP-model. We assumed that reactive aggression is related to early-stage processing (i.e. early steps in the SIP-model, such as attention, interpretation) while proactive aggression is related to later-stage processing (i.e. later steps in the SIP-model, such as response access, response selection) ${ }^{1}$ This assumption was based upon

\footnotetext{
${ }^{1}$ Please note that the terms 'early' and 'late' stage that we use, do not point to the distinction between automatic and controlled processes. It merely reflects the placement of the stages of the SIP-model (e.g. encoding is an early-stage process, as it is the first step of the model, while response decision is a late-stage process as it is one of the last steps of the model). The SIP-model of Crick and
}

the findings of the study Crick and Dodge (1996), in which they found a link between reactive aggression and hostile intent attributions (early stage processing) on the one hand and response decision processes (late stage processing) on the other hand. In our study, it was expected that higher levels of reactive aggression would be predicted by a heightened attentional interference of aggressive stimuli and angry faces and aggression-related biases. Furthermore, it was expected that a stronger self-aggression association (which we consider to be quite similar to the measurement of behavioral scripts) would predict more proactive aggression. A more explorative approach was taken with regards to an open-ended vignette task. Aggressive behavior was examined with two instruments: the Reactive Proactive Aggression Paradigm (RPQ) and the Taylor Aggression Paradigm (TAP). Both instruments have their benefits (e.g. the RPQ is easy to use, time-effective, and well validated, while the TAP better resembles real-life aggression) and downsides (self-report measures such as the RPQ are often influenced by social desirable answering, while the downside of the TAP is that it does not incorporate the specific triggers for an individual to react aggressively). Both aggression measures should adequately complement each other in the measurement of reactive and aggressive behavior.

To our knowledge, this study is the first to examine the predictive value of these three cognitive processes in predicting reactive and proactive aggression in a forensic sample and to directly compare the findings with earlier non-clinical findings, thereby testing similarities and differences in cognitive factors underlying reactive and proactive aggression.

\section{Methods}

\subsection{Participants}

Data were collected of $N=87$ male patients $\left(M_{\text {age }}=40.3\right.$, $S D=10.5)$. Only males participated, due to established gender differences in aggressive behavior (Archer, 2004). Sixty patients were recruited at a forensic psychiatric hospital or so-called 'TBS-clinic' . 2 Seven patients were recruited at a long-term forensic psychiatric care department.. Twenty patients were recruited at an outpatient treatment center of psychiatric clients who have been in contact with the law or are at risk. Patients with a current - or history of - psychosis were excluded from the study. Furthermore, only patients with an IQ-level of 80 or higher were included in the present study. IQ levels were based on either the Dutch version of the National Adult Reading task (NLV; Schmand et al., 1991), or on previously completed intelligence tests that could be found in the patient files (e.g. WAIS, GIT). If no information was available on IQ-level, patients could be included in the study on the basis of the clinicians' judgment that there was no sign of mental retardation. Descriptive statistics for age, nationality, educational level, DSM diagnoses (established by mental health professionals), type of index crime, and mean PCL-R score (Psychopathy Checklist-Revised; Hare, 1991) can be found in Table 1.

Data of this study was compared with the non-clinical sample used in Brugman et al. (2015; $N=98, M_{\text {age }}=27.1, S D_{\text {age }}=10.5$, age range: 18-54 years). Participants were recruited by using posters, flyers, and social media. They participated in exchange for study credits or $€ 20$,- in vouchers. Descriptive statistics for age, nationality, and educational

\section{(footnote continued)}

Dodge (1994) includes both automatic as well as controlled processes. Dodge (2008) argues that reactive and proactive aggression is both linked to automatic and controlled processes.

2 TBS or 'terbeschikkingstelling' can be translated as "disposal to be treated on behalf of the state'. In the Nederlands, if a person commits a serious criminal offense that is likely to be the results of his mental disorder, he is not liable or has diminished responsibility for this crime. If he is a serious danger to society or himself, this person will be submitted to a secure institution through an entrustment act. 
Table 1

Descriptive statistics of forensic and non-clinical sample.

\begin{tabular}{|c|c|c|}
\hline Descriptives & Forensic & Non-clinical \\
\hline Age, mean (SD) & $40.2(10.5)$ & $27.1(10.5)$ \\
\hline \multicolumn{3}{|l|}{ Nationality, N (\%) } \\
\hline Dutch & $85(97.7)$ & $89(90.8)$ \\
\hline Moroccan & $1(1.1)$ & $1(1.0)$ \\
\hline Kosovar & $1(1.1)$ & 0 \\
\hline German & 0 & $1(1.0)$ \\
\hline Iranian & 0 & $1(1.0)$ \\
\hline Belgian & 0 & $3(3.1)$ \\
\hline Thai & 0 & $1(1.0)$ \\
\hline Iraqi & 0 & $1(1.0)$ \\
\hline Greek & 0 & $1(1.0)$ \\
\hline \multicolumn{3}{|l|}{ Educational level $^{\mathrm{a}}$} \\
\hline Did not finish primary school & $1(1.3)$ & 0 \\
\hline Finished primary school & $20(25.0)$ & 0 \\
\hline $\begin{array}{l}\text { Finished secondary education (LBO, MAVO, } \\
\text { HAVO, VWO) }\end{array}$ & $41(51.3)$ & $8(8.2)$ \\
\hline $\begin{array}{l}\text { Finished middle level professional education } \\
(\mathrm{MBO})\end{array}$ & $14(17.5)$ & $8(8.2)$ \\
\hline $\begin{array}{l}\text { Finished higher level professional education } \\
\text { (HBO) }\end{array}$ & $3(3.8)$ & $11(11.2)$ \\
\hline Currently student at university & 0 & $65(66.3)$ \\
\hline University degree or higher & 0 & $2(2.0)$ \\
\hline $\mathrm{IQ}^{\mathrm{b}}$, mean $(\mathrm{SD})$ & $95.1(9.7)$ & N/A \\
\hline NLV-based IQ ${ }^{c}$ & $89.8(8.6)$ & $\mathrm{N} / \mathrm{A}$ \\
\hline \multicolumn{3}{|l|}{ Axis I diagnosis, N (\%) } \\
\hline $\begin{array}{l}\text { Attention deficit and disruptive behavior } \\
\text { disorder }\end{array}$ & $11(13.8)$ & N/A \\
\hline Developmental disorders & $4(5.0)$ & $\mathrm{N} / \mathrm{A}$ \\
\hline $\begin{array}{l}\text { Other disorders of infancy, childhood, and } \\
\text { adolescence }\end{array}$ & $2(2.5)$ & N/A \\
\hline Mood disorders & $8(10)$ & $\mathrm{N} / \mathrm{A}$ \\
\hline Anxiety disorder/PTSS & $7(8.8)$ & N/A \\
\hline Somatization disorder & $1(1.3)$ & N/A \\
\hline Dissociative disorder & $1(1.3)$ & N/A \\
\hline Sexual and gender identity disorders & $22(27.5)$ & N/A \\
\hline Eating disorders & $1(1.3)$ & N/A \\
\hline Impulse control disorders & $11(13.8)$ & N/A \\
\hline Substance-related disorders & $34(42.5)$ & N/A \\
\hline $\begin{array}{l}\text { Delirium, dementia, and amnestic and other } \\
\text { cognitive disorders }\end{array}$ & $1(1.3)$ & N/A \\
\hline Adjustment disorders & $1(1.3)$ & N/A \\
\hline \multicolumn{3}{|l|}{ Axis II diagnosis, $\mathrm{N}(\%)$} \\
\hline Paranoid PD & $4(5)$ & $\mathrm{N} / \mathrm{A}$ \\
\hline Antisocial PD & $37(46.3)$ & N/A \\
\hline Borderline PD & $14(17.5)$ & $\mathrm{N} / \mathrm{A}$ \\
\hline Narcissistic PD & $10(12.5)$ & N/A \\
\hline Avoidant PD & $3(3.8)$ & N/A \\
\hline Obsessive-Compulsive PD & $1(1.3)$ & $\mathrm{N} / \mathrm{A}$ \\
\hline Personality disorder NAO & $33(41.3)$ & \\
\hline With paranoid features & $4(5)$ & $\mathrm{N} / \mathrm{A}$ \\
\hline With schizoid features & $1(1.3)$ & $\mathrm{N} / \mathrm{A}$ \\
\hline With antisocial features & $22(27.5)$ & N/A \\
\hline With borderline features & $14(17.5)$ & N/A \\
\hline With histrionic features & $4(5)$ & N/A \\
\hline With narcisstic features & $24(30)$ & N/A \\
\hline With avoidant features & $9(11.3)$ & $\mathrm{N} / \mathrm{A}$ \\
\hline With dependent features & $6(7.5)$ & N/A \\
\hline With obsessive-compulsive features & $1(1.3)$ & $\mathrm{N} / \mathrm{A}$ \\
\hline $\begin{array}{l}\text { Amount of participants with PCL-R score of } \geq 26, \mathrm{~N} \\
(\%)\end{array}$ & $31.1^{\mathrm{d}}$ & $\mathrm{N} / \mathrm{A}$ \\
\hline
\end{tabular}

${ }^{\text {a }}$ Information on educational level was not available for 4 participants in the non-clinical sample.

b Information on IQ-score was unavailable for 25 participants in the forensic sample. Please note that only four patients do not have any IQ-information on either file-base or on the NLV. IQ-levels were not available for the non-clinical sample.

c Information on NLV-based IQ-score was unavailable for 16 participants of the forensic sample. Please note that only four patients do not have any IQinformation on either file-base or on the NLV. The NLV was not executed in the non-clinical sample.

d Information on PCL-R scores were available for 48 of the 87 participants. Of these 48 participants, $31.1 \%$ can be indicated as psychopathic. level can be found in Table 1 . More information on the sample can be found in Brugman et al. (2015).

Participants of the non-clinical sample significantly differ from forensic patients in terms of educational level. A Mann-Whitney $U$ test (Mann-Whitney $\mathrm{U}=396.5, p<0.001$ indicated that the educational level was higher in the non-clinical sample $(\mathrm{Mdn}=6)$ than in the forensic group ( $\mathrm{Mdn}=3$ ). This difference was expected, as unfinished education is one of the intrinsic characteristics of forensic samples due to conduct disorder and/or other behavioral- and emotional problems during adolescence. Therefore, we did not choose to include educational level as a covariate in the analyses. Regarding the ethnical background of participants, there was no difference between groups (Mann-Whitney $U=3650.5$, non-clinical sample $=1$, forensic sample $=1, p=0.06$ ). In both groups, the majority of men were Dutch.

\subsection{Materials}

\subsubsection{Emotional Stroop Task}

Attentional interference of aggressive stimuli was measured with the Emotional Stroop Task (Brugman et al., 2015). A detailed description of the task can be found in the Supplementary Material.

\subsubsection{Single-Target Implicit Association Task}

A Single-Target Implicit Association Task (ST-IAT; Karpinski and Steinman, 2006) was used to measure an automatic self-aggression association (see Brugman et al., 2015). See Supplementary Material for a detailed description.

\subsubsection{Visual Search Task}

Attentional bias for emotional faces was measured with a visual search task (VST), which is described in the Supplementary Material.

\subsubsection{Aggressive Interpretative Bias Task}

The Aggressive Interpretative Bias Task (AIBT) was used to measure a tendency to interpret ambiguous sentences as aggressive. A detailed description of the AIBT can be found in the Supplementary Material.

\subsubsection{Vignettes}

Vignettes, or short stories describing a hypothetical situation, were used to measure the interpretation of ambiguous situations. This task was previously used in Brugman et al. (2015) and based on the vignettes used in the study of Lobbestael et al (2013). ${ }^{3}$ Further details on the task can be found in the Supplementary Material.

\subsubsection{Reactive Proactive Aggression Questionnaire}

The Dutch translation (Cima et al., 2013) of the Reactive Proactive Aggression Questionnaire (RPQ; Raine et al., 2006) was used to measure self-reported aggressiveness. Details and information on reliability of the scale can be found in the Supplementary Material. Standardized residuals of reactive and proactive aggression were calculated for the total sample (by controlling reactive aggression for proactive aggression and vice versa) and used in further analyses. See Raine et al. (2006) as well as Cima and Raine (2009) for an elaborate discussion on the superiority of using this approach.

\subsubsection{Taylor Aggression Paradigm}

The Taylor Aggression Paradigm (TAP; Taylor, 1967) was used to measure aggressive behavior. The settings and procedure of the task was similar to Brugman et al. (2015). Further information on the task and on the analyses required to obtain the factors from the TAP scores, can be found in the Supplementary Material.

\footnotetext{
${ }^{3}$ The vignettes can be requested by contacting the first author
} 


\subsection{Procedure}

Clinicians were asked whether selected patients, meeting the inclusion criteria, could be contacted for the study. Next, selected patients were asked to participate and provided with verbal and written information about the study. Participants were asked whether they had hearing problems. If so, they excluded due to the noises administered in the TAP. If a patient agreed to participate, two $1 \mathrm{~h}$ meetings were planned. During the first test session, ${ }^{4}$ participants signed informed consent and demographic information was obtained. At the end of the experiment, a manipulation check was administered. After the study, patients received written information about the cover story and purpose of the study. This study was approved by the Ethical Committee Psychology of Maastricht University, The Netherlands.

\subsection{Statistical analyses}

Regression analyses were used to test the predictive value of the cognitive tasks. ${ }^{5}$ For each regression analysis, a group (non-clinical vs. forensic) $\mathrm{x}$ task (cognitive task) design was used with the standardized residuals of RPQ reactive, or RPQ proactive, TAP reactive factor, or TAP proactive factor as dependent variable. ${ }^{6}$ This way, it was tested whether the task predicted aggression in both groups in the same manner (task effect), or whether the task predicted aggression in both groups differently (group $x$ task interaction effect). The manipulation check revealed that 14 out of the 80 participants of the forensic sample that completed the TAP did not completely believe cover story and were excluded from the analyses with the TAP as dependent variable.

\section{Results}

\subsection{Preliminary analyses}

A total of 87 forensic patients were tested. Six participants were eliminated as their IQ-scores on the NLV were below 80 and their patient files did not include any additional information on IQ. One additional patient did not have any Axis-II diagnosis and was therefore excluded from further analyses, leaving a final sample of 80 . Mahalanobis distance (Barnett, et al. 1978) was used to eliminate outliers on the cognitive tasks (see Supplementary material for number of outliers eliminated per task).

\subsection{Descriptives}

Means of the forensic $(N=80)$ and the non-clinical sample $(N=98$; see Brugman et al. 2015) of reactive and proactive self-reported and behavioral aggression and performance on the cognitive tasks can be found in Table 2. Zero-order correlations between the measures for each sample can be found in Table 3 .

\subsection{Regression analyses with the RPQ as dependent measure}

In all models predicting self-reported proactive aggression, a significant regression equation was found for the variable 'group' . This finding implies that overall, participants of the non-clinical sample reported significantly lower residualized proactive aggression than

\footnotetext{
${ }^{4}$ Participants were assigned to one of four conditions, in which the order of the cognitive tasks was counterbalanced. The RPQ and TAP were always completed last.

${ }^{5}$ Selection of the mean/bias scores of all our implicit measures were based on best-practice approaches from an extended literature search of each measure. One clear advantage of this approach is that allows direct comparison with other studies using the same tasks.

${ }^{6}$ All predictors were centered for this analysis and group membership was coded as -1 (non-clinical) and 1 (forensic).
}

forensic patients (means can be found in Table 2; $F(1170)=10.66$, $p=0.001$ ). Participants of the non-clinical sample did not differ on residualized reactive aggression from the forensic patients (Table 2; $F$ $(1,170)=1.38, p=0.24)$.

\subsubsection{Emotional Stroop}

The Emotional Stroop or the interaction between the Emotional Stroop and group level did not significantly predict self-reported aggression.

\subsubsection{VST}

The VST or the interaction between the VST and group level were no significant predictors of self-reported aggression.

\subsubsection{ST-IAT}

A significant regression equation was found for the prediction of proactive aggression $(F(3165)=7.33, p<0.01)$. The ST-IAT was found to be a significant predictor of self-reported proactive aggression. A stronger self-aggression association on the ST-IAT predicted higher selfreported proactive aggression (Table 4). A significant regression equation was also found for group x ST-IAT (Table 4, Fig. 1). A simple regression analysis on both groups separately showed that the ST-IAT did not predict self-reported proactive aggression in the non-clinical sample $(\mathrm{F}(194)=0.037, p=0.85, t=0.19, \beta=0.02)$, whereas the ST-IAT did predict self-reported proactive aggression in the forensic sample $(F$ $(171)=8.82, p<0.01, \beta=0.33, t=2.97, R^{2}=0.11$ ).

\subsubsection{AIBT}

The AIBT or the interaction between the AIBT and group level did not significantly predict self-reported aggression.

\subsubsection{Vignettes}

None of the themes significantly predicted self-reported reactive aggression. A significant regression equation was found for the theme 'pain/injury/danger' on self-reported proactive aggression ( $F$ $\left.(3163)=5.53, p<0.001, R^{2}=0.09\right)$. Higher reports of pain, injury and danger during the vignette-task predicted lower proactive aggression on the RPQ in both samples (Table 4). None of the other themes significantly predicted self-reported proactive aggression.

\subsection{Regression analyses with the TAP as dependent measure}

In all models predicting TAP proactive aggression, a significant regression equation was found for the variable 'group' .. Overall, participants from the non-clinical sample showed significantly less proactive aggression than forensic patients (means in Table 2; $F(1154)=30.79$, $p<0.001$ ). Group level was not predictive of TAP reactive aggression. Overall, participants from the non-clinical sample showed levels of TAP reactive aggression not significantly different from forensic patients (means in Table $2 ; F(1154)=2.60, p=0.11$ ).

\subsubsection{Emotional Stroop}

The Emotional Stroop was not a significant predictor of reactive aggression measured with the TAP. A significant regression equation was found for the prediction of TAP proactive $(F(3138)=9.96$, $p=0.001, R^{2}=0.19$ ). The interaction between interference of aggressive words and group level significantly predicted proactive aggression on the TAP (Table 4, Fig. 2). Regression analyses on both groups separately showed a trend for the predictive value of the Emotional Stroop only in the non-clinical sample $(F(183)=3.45, p=0.07$, $\beta=-0.20, t=-1.86)$ whereas this was not found in the forensic sample $(F(157)=0.92, p=0.34)$.

\subsubsection{VST}

The VST or the interaction between the VST and group level did not significantly predict aggressive behavior on the TAP. 


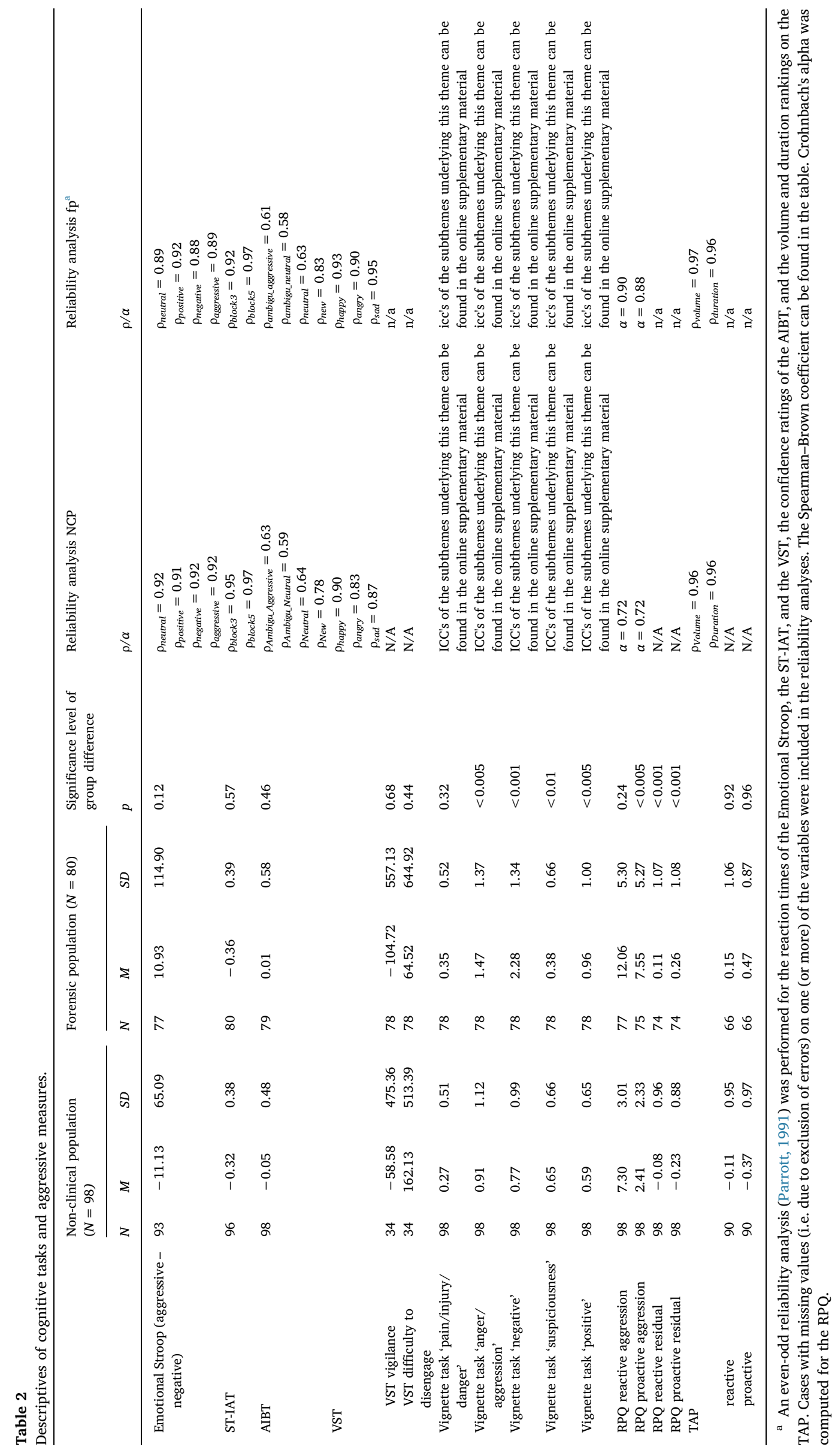


Table 3

Zero-order correlations of the cognitive tasks and aggressive measures.

\begin{tabular}{|c|c|c|c|c|c|c|c|c|c|c|c|c|c|c|c|}
\hline \multirow{2}{*}{\multicolumn{2}{|c|}{$\mathrm{NCP}$}} & 1 & 2 & \multirow[t]{2}{*}{3} & \multirow[t]{2}{*}{4} & \multirow[t]{2}{*}{5} & \multirow[t]{2}{*}{6} & \multirow[t]{2}{*}{7} & \multirow[t]{2}{*}{8} & \multirow[t]{2}{*}{9} & \multirow[t]{2}{*}{10} & \multirow[t]{2}{*}{11} & \multirow[t]{2}{*}{12} & \multirow[t]{2}{*}{13} & \multirow[t]{2}{*}{14} \\
\hline & & & & & & & & & & & & & & & \\
\hline 1 & $\begin{array}{l}\text { Emotional } \\
\text { Stroop }\end{array}$ & & $\begin{array}{l}- \\
0.1 \\
47\end{array}$ & 77 & $\begin{array}{l}- \\
0.0 \\
27\end{array}$ & $\begin{array}{l}- \\
0.03 \\
1\end{array}$ & $\begin{array}{l}- \\
0.1 \\
66\end{array}$ & $\begin{array}{l}0.10 \\
8\end{array}$ & $\begin{array}{l}- \\
0.11 \\
3\end{array}$ & $\begin{array}{l}- \\
0.10 \\
8\end{array}$ & $\begin{array}{l}- \\
0.1 \\
52\end{array}$ & $\begin{array}{l}- \\
0.07 \\
9\end{array}$ & $\begin{array}{l}- \\
0.03 \\
2\end{array}$ & $\begin{array}{l}- \\
0.0 \\
72\end{array}$ & $\begin{array}{l}0.1 \\
69\end{array}$ \\
\hline 2 & ST-IAT & $\begin{array}{l}0.0 \\
70\end{array}$ & & $-\overline{0.0}$ & $\begin{array}{l}0.0 \\
75\end{array}$ & $\begin{array}{l}0.09 \\
0\end{array}$ & $\begin{array}{l}0.1 \\
30\end{array}$ & $\begin{array}{l}0.11 \\
2\end{array}$ & $\begin{array}{l}- \\
0.15 \\
1\end{array}$ & $\begin{array}{l}0.00 \\
5\end{array}$ & $\begin{array}{l}- \\
0.0 \\
20\end{array}$ & $\begin{array}{l}0.16 \\
4\end{array}$ & $\begin{array}{l}0.30 \\
4^{* *}\end{array}$ & $\begin{array}{l}0.2 \\
00\end{array}$ & $\begin{array}{l}0.2 \\
51^{*}\end{array}$ \\
\hline 3 & AIBT & $\begin{array}{l}0.0 \\
29\end{array}$ & $\begin{array}{l}0.1 \\
61\end{array}$ & & & $\begin{array}{l}0.07 \\
4\end{array}$ & $\begin{array}{l}0.0 \\
14\end{array}$ & $\begin{array}{l}- \\
0.10 \\
6\end{array}$ & $\begin{array}{l}- \\
0.03 \\
7\end{array}$ & $\begin{array}{l}- \\
0.04 \\
3\end{array}$ & $\begin{array}{l}- \\
0.0 \\
01\end{array}$ & $\begin{array}{l}- \\
0.19 \\
2\end{array}$ & $\begin{array}{l}- \\
0.26 \\
8^{*}\end{array}$ & $\begin{array}{l}- \\
0.1 \\
06\end{array}$ & $\begin{array}{l}- \\
0.1 \\
31\end{array}$ \\
\hline 4 & $\begin{array}{l}\text { VST } \\
\text { vigilance }\end{array}$ & $\begin{array}{l}0.0 \\
60\end{array}$ & $\begin{array}{l}0.3 \\
02\end{array}$ & & & $\begin{array}{l}- \\
0.33 \\
7^{* *}\end{array}$ & $\begin{array}{l}0.0 \\
28\end{array}$ & $\begin{array}{l}0.09 \\
3\end{array}$ & $\begin{array}{l}- \\
0.08 \\
0\end{array}$ & $\begin{array}{l}0.03 \\
2\end{array}$ & $\begin{array}{l}0.1 \\
42\end{array}$ & $\begin{array}{l}0.12 \\
4\end{array}$ & $\begin{array}{l}0.20 \\
5\end{array}$ & $\begin{array}{l}0.1 \\
56\end{array}$ & $\begin{array}{l}0.0 \\
29\end{array}$ \\
\hline 5 & $\begin{array}{l}\text { VST } \\
\text { difficulty to } \\
\text { disengage }\end{array}$ & $\begin{array}{l}- \\
0.0 \\
27\end{array}$ & $\begin{array}{l}0.2 \\
03\end{array}$ & $\begin{array}{l}0.1 \\
99\end{array}$ & $\begin{array}{l}- \\
0.0 \\
46\end{array}$ & & & $\begin{array}{l}0.06 \\
4\end{array}$ & $\begin{array}{l}0.01 \\
3\end{array}$ & $\begin{array}{l}0.24 \\
2^{*}\end{array}$ & $\begin{array}{l}- \\
0.0 \\
84\end{array}$ & $\begin{array}{l}- \\
0.14 \\
2\end{array}$ & $\begin{array}{l}- \\
0.17 \\
9\end{array}$ & $\begin{array}{l}- \\
0.1 \\
06\end{array}$ & $\begin{array}{l}- \\
0.0 \\
45\end{array}$ \\
\hline 6 & $\begin{array}{l}\text { Vignette } \\
\text { task } \\
\text { 'pain/injury } \\
\text { /danger' }\end{array}$ & $\begin{array}{l}0.0 \\
54\end{array}$ & $\begin{array}{l}- \\
0.1 \\
14\end{array}$ & $\begin{array}{l}- \\
0.1 \\
63\end{array}$ & $\begin{array}{l}- \\
0.2 \\
12\end{array}$ & & & $\begin{array}{l}- \\
0.22 \\
1\end{array}$ & $\begin{array}{l}0.15 \\
5\end{array}$ & $\begin{array}{l}0.10 \\
7\end{array}$ & $\begin{array}{l}0.1 \\
76\end{array}$ & $\begin{array}{l}0.00 \\
2\end{array}$ & $\begin{array}{l}- \\
0.14 \\
1\end{array}$ & $\begin{array}{l}0.0 \\
16\end{array}$ & $\begin{array}{l}0.0 \\
39\end{array}$ \\
\hline 7 & $\begin{array}{l}\text { Vignette } \\
\text { task } \\
\text { 'anger/aggr } \\
\text { ession' }\end{array}$ & $\begin{array}{l}- \\
0.0 \\
67\end{array}$ & $\begin{array}{l}- \\
0.0 \\
13\end{array}$ & $\begin{array}{l}0.0 \\
33\end{array}$ & $\begin{array}{l}- \\
0.0 \\
90\end{array}$ & $\begin{array}{l}0.00 \\
8\end{array}$ & $\begin{array}{l}- \\
0.1 \\
61\end{array}$ & 1 & $\begin{array}{l}0.14 \\
5\end{array}$ & $\begin{array}{l}0.27 \\
2^{*}\end{array}$ & $\begin{array}{l}- \\
0.0 \\
27\end{array}$ & $\begin{array}{l}0.47 \\
5^{* *}\end{array}$ & $\begin{array}{l}0.44 \\
2^{* *}\end{array}$ & $\begin{array}{l}0.2 \\
87^{*}\end{array}$ & $\begin{array}{l}0.1 \\
86\end{array}$ \\
\hline 8 & $\begin{array}{l}\text { Vignette } \\
\text { task } \\
\text { 'negative' }\end{array}$ & $\begin{array}{l}0.1 \\
16\end{array}$ & $\begin{array}{l}- \\
0.1 \\
13\end{array}$ & $\begin{array}{l}- \\
0.0 \\
92\end{array}$ & $\begin{array}{l}- \\
0.2 \\
61\end{array}$ & $\begin{array}{l}- \\
0.10 \\
6\end{array}$ & $\begin{array}{l}0.1 \\
66\end{array}$ & $\begin{array}{l}0.32 \\
6^{* *}\end{array}$ & & $\begin{array}{l}0.35 \\
2^{* *}\end{array}$ & $\begin{array}{l}0.0 \\
57\end{array}$ & $\begin{array}{l}0.11 \\
4\end{array}$ & $\begin{array}{l}0.00 \\
3\end{array}$ & $\begin{array}{l}0.1 \\
15\end{array}$ & $\begin{array}{l}0.0 \\
57\end{array}$ \\
\hline 9 & $\begin{array}{l}\text { Vignette } \\
\text { task } \\
\text { 'suspicious } \\
\text { ness' }\end{array}$ & $\begin{array}{l}0.0 \\
66\end{array}$ & $\begin{array}{l}0.1 \\
50\end{array}$ & $\begin{array}{l}- \\
0.0 \\
82\end{array}$ & $\begin{array}{l}0.1 \\
36\end{array}$ & $\begin{array}{l}0.17 \\
1\end{array}$ & $\begin{array}{l}- \\
0.0 \\
09\end{array}$ & $\begin{array}{l}0.07 \\
2\end{array}$ & $\begin{array}{l}- \\
0.00 \\
1\end{array}$ & 1 & $\begin{array}{l}0.1 \\
00\end{array}$ & $\begin{array}{l}0.13 \\
5\end{array}$ & $\begin{array}{l}0.10 \\
2\end{array}$ & $\begin{array}{l}0.0 \\
95\end{array}$ & $\begin{array}{l}- \\
0.0 \\
85\end{array}$ \\
\hline $\begin{array}{l}1 \\
0\end{array}$ & $\begin{array}{l}\text { Vignette } \\
\text { task } \\
\text { 'positive' }\end{array}$ & $\begin{array}{l}- \\
0.0 \\
50\end{array}$ & $\begin{array}{l}- \\
0.1 \\
19\end{array}$ & $\begin{array}{l}0.0 \\
78\end{array}$ & $\begin{array}{l}- \\
0.0 \\
92\end{array}$ & $\begin{array}{l}- \\
0.29 \\
3\end{array}$ & $\begin{array}{l}0.1 \\
63\end{array}$ & $\begin{array}{l}0.20 \\
7^{*}\end{array}$ & $\begin{array}{l}0.27 \\
4^{* *}\end{array}$ & $\begin{array}{l}0.09 \\
3\end{array}$ & & $\begin{array}{l}0.02 \\
7\end{array}$ & $\begin{array}{l}0.06 \\
3\end{array}$ & $\begin{array}{l}0.2 \\
20\end{array}$ & $\begin{array}{l}- \\
0.1 \\
76\end{array}$ \\
\hline $\begin{array}{l}1 \\
1\end{array}$ & $\begin{array}{l}\text { RPQ } \\
\text { reactive } \\
\text { aggression }\end{array}$ & $\begin{array}{l}- \\
0.1 \\
53\end{array}$ & $\begin{array}{l}0.0 \\
96\end{array}$ & $\begin{array}{l}0.0 \\
26\end{array}$ & $\begin{array}{l}- \\
0.1 \\
26\end{array}$ & $\begin{array}{l}0.38 \\
6^{*}\end{array}$ & $\begin{array}{l}0.0 \\
10\end{array}$ & $\begin{array}{l}- \\
0.03 \\
5\end{array}$ & $\begin{array}{l}- \\
0.05 \\
1\end{array}$ & $\begin{array}{l}0.05 \\
5\end{array}$ & $\begin{array}{l}0.0 \\
38\end{array}$ & & $\begin{array}{l}0.82 \\
8^{* *}\end{array}$ & $\begin{array}{l}0.2 \\
66^{*}\end{array}$ & $\begin{array}{l}0.2 \\
42\end{array}$ \\
\hline $\begin{array}{l}1 \\
2\end{array}$ & $\begin{array}{l}\text { RPQ } \\
\text { proactive } \\
\text { aggression }\end{array}$ & $\begin{array}{l}- \\
0.1 \\
45\end{array}$ & $\begin{array}{l}0.1 \\
20\end{array}$ & $\begin{array}{l}0.0 \\
71\end{array}$ & $\begin{array}{l}- \\
0.1 \\
59\end{array}$ & $\begin{array}{l}- \\
0.08 \\
3\end{array}$ & $\begin{array}{l}- \\
0.1 \\
11\end{array}$ & $\begin{array}{l}0.01 \\
9\end{array}$ & $\begin{array}{l}- \\
0.10 \\
2\end{array}$ & $\begin{array}{l}- \\
0.04 \\
8\end{array}$ & $\begin{array}{l}0.0 \\
04\end{array}$ & $\begin{array}{l}0.47 \\
2^{* *}\end{array}$ & & $\begin{array}{l}0.2 \\
96^{*}\end{array}$ & $\begin{array}{l}0.1 \\
90\end{array}$ \\
\hline $\begin{array}{l}1 \\
3\end{array}$ & $\begin{array}{l}\text { TAP } \\
\text { reactive } \\
\text { aggression }\end{array}$ & $\begin{array}{l}0.1 \\
40\end{array}$ & $\begin{array}{l}0.0 \\
22\end{array}$ & $\begin{array}{l}0.2 \\
32^{*}\end{array}$ & $\begin{array}{l}0.2 \\
19\end{array}$ & $\begin{array}{l}0.15 \\
6\end{array}$ & $\begin{array}{l}- \\
0.0 \\
05\end{array}$ & $\begin{array}{l}- \\
0.01 \\
7\end{array}$ & $\begin{array}{l}- \\
0.04 \\
7\end{array}$ & $\begin{array}{l}0.16 \\
2\end{array}$ & $\begin{array}{l}0.1 \\
54\end{array}$ & $\begin{array}{l}- \\
0.04 \\
9\end{array}$ & $\begin{array}{l}- \\
0.09 \\
2\end{array}$ & & $\begin{array}{l}- \\
0.1 \\
30\end{array}$ \\
\hline $\begin{array}{l}1 \\
4\end{array}$ & $\begin{array}{l}\text { TAP } \\
\text { proactive } \\
\text { aggression }\end{array}$ & $\begin{array}{l}- \\
0.2 \\
00\end{array}$ & $\begin{array}{l}0.1 \\
80\end{array}$ & $\begin{array}{l}- \\
0.0 \\
46\end{array}$ & $\begin{array}{l}0.0 \\
19\end{array}$ & $\begin{array}{l}0.09 \\
1\end{array}$ & $\begin{array}{l}0.1 \\
55\end{array}$ & $\begin{array}{l}- \\
0.00 \\
5\end{array}$ & $\begin{array}{l}0.02 \\
7\end{array}$ & $\begin{array}{l}0.07 \\
9\end{array}$ & $\begin{array}{l}0.0 \\
04\end{array}$ & $\begin{array}{l}- \\
0.04 \\
3\end{array}$ & $\begin{array}{l}- \\
0.02 \\
9\end{array}$ & $\begin{array}{l}- \\
0.0 \\
31\end{array}$ & \\
\hline
\end{tabular}

Note: NCP = Non-clinical population, depicted in the lower half of the table; FP=forensic population, depicted in the upper half of the table.

\subsubsection{ST-IAT}

The ST-IAT or the interaction between the ST-IAT and group level did not significantly predict TAP reactive aggression. A significant regression equation was found for predicting proactive aggression $(F$ $\left.(3150)=12.77, p=0.001, R^{2}=0.20\right)$. The ST-IAT was found to be a significant predictor of proactive aggression (Table 4): in both groups a stronger self-aggression association predicted more proactive aggression on the TAP.

\subsubsection{AIBT}

A significant regression equation was found for predicting TAP reactive aggression $\left(F(3,151)=2.77, p=0.04, R^{2}=0.05\right)$. The interaction between the AIBT and group level was found to significantly predict reactive aggression.(Table 4, Fig. 3). A simple regression analysis for both groups separately showed that the AIBT predicted reactive aggression on the TAP only in the non-clinical sample $(F(188)=5.03$, $p=0.03, R^{2}=0.06$ ); more confidence of having seen aggressive 
Table 4

Results of the regression analyses examining the effects of the cognitive tasks in predicting self-reported and behavioral aggression.

\begin{tabular}{|c|c|c|c|c|c|c|c|c|c|c|c|c|c|}
\hline \multirow[t]{2}{*}{ Task } & \multirow[t]{2}{*}{ Model variables } & \multicolumn{3}{|c|}{ Reactive aggression $R P Q$} & \multicolumn{3}{|c|}{ Proactive aggression $R P Q$} & \multicolumn{3}{|c|}{ Reactive aggression TAP } & \multicolumn{3}{|c|}{ Proactive aggression TAP } \\
\hline & & $\beta$ & $t$ & $p$ & $\beta$ & $t$ & $p$ & $\beta$ & $t$ & $p$ & $\beta$ & $t$ & $p$ \\
\hline \multirow[t]{3}{*}{ Emotional stroop } & Group & 0.06 & 0.77 & 0.44 & 0.29 & 3.72 & $<0.001^{* *}$ & 0.11 & 1.29 & 0.20 & 0.40 & 5.17 & $<0.001^{* *}$ \\
\hline & Task & -0.08 & -1.02 & 0.31 & -0.01 & -0.18 & 0.86 & 0.05 & 0.58 & 0.57 & -0.07 & -0.88 & 0.38 \\
\hline & Group $\mathrm{x}$ task & 0.01 & -0.15 & 0.88 & -0.02 & -0.30 & 0.77 & -0.12 & -1.33 & 0.19 & 0.16 & 2.03 & $0.04 *$ \\
\hline \multirow[t]{3}{*}{ VST vigilance } & Group & -0.01 & -0.05 & 0.96 & 0.26 & 2.70 & $0.01 *$ & 0.08 & 0.73 & 0.47 & 0.35 & 3.67 & $<0.001^{* * *}$ \\
\hline & Task & -0.06 & -0.62 & 0.54 & 0.13 & 1.40 & 0.17 & 0.12 & 1.20 & 0.23 & 0.01 & 0.10 & 0.92 \\
\hline & Group $\mathrm{x}$ task & -0.08 & -0.69 & 0.49 & 0.150 & 1.316 & 0.191 & 0.07 & 0.53 & 0.60 & 0.03 & 0.26 & 0.79 \\
\hline \multirow[t]{3}{*}{ VST difficulty to disengage } & Group & 0.01 & 0.09 & 0.93 & 0.24 & 2.54 & $0.01 *$ & 0.04 & 0.35 & 0.73 & 0.35 & 3.64 & $<0.001^{* * *}$ \\
\hline & Task & 0.09 & 0.91 & 0.36 & -0.16 & -1.71 & 0.09 & -0.04 & -0.37 & 0.71 & -0.0 & -0.01 & 0.99 \\
\hline & Group $\mathrm{x}$ task & -0.27 & -2.51 & $0.01 *$ & 0.17 & 1.63 & 0.11 & -0.14 & -1.14 & 0.26 & 0.04 & 0.37 & 0.71 \\
\hline \multirow[t]{3}{*}{ STIAT } & Group & 0.08 & 0.99 & 0.32 & 0.27 & 3.62 & $<0.001^{* *}$ & 0.12 & 1.55 & 0.12 & 0.42 & 5.73 & $<0.001^{* * *}$ \\
\hline & Task & -0.08 & -1.07 & 0.29 & 0.19 & 2.55 & $0.01 *$ & 0.11 & 1.42 & 0.16 & 0.19 & 2.62 & $0.01 *$ \\
\hline & Group $\mathrm{x}$ task & -0.10 & -1.34 & 0.18 & 0.17 & 2.32 & $0.02^{*}$ & 0.09 & 1.16 & 0.25 & 0.02 & 0.29 & 0.77 \\
\hline \multirow[t]{3}{*}{ AIBT } & Group & 0.09 & 1.20 & 0.23 & 0.24 & 3.29 & $<0.001^{* * *}$ & 0.13 & 1.64 & 0.10 & 0.41 & 5.48 & $<0.001^{* *}$ \\
\hline & Task & 0.02 & 0.31 & 0.76 & -0.09 & -1.22 & 0.22 & 0.07 & 0.89 & 0.38 & -0.08 & -1.01 & 0.32 \\
\hline & Group $\mathrm{x}$ task & 0.05 & 0.60 & 0.55 & -0.13 & -1.77 & 0.08 & -0.17 & -2.16 & $0.03^{*}$ & -0.03 & -0.36 & 0.72 \\
\hline \multirow[t]{3}{*}{ Vignettes pain/injury/danger } & Group & 0.07 & 0.94 & 0.35 & 0.26 & 3.47 & $<0.001^{* *}$ & 0.11 & 1.35 & 0.18 & 0.39 & 5.17 & $<0.001^{* * *}$ \\
\hline & Task & 0.14 & 1.81 & 0.07 & -0.17 & -2.26 & $0.03^{*}$ & 0.02 & 0.25 & 0.81 & 0.09 & 1.19 & 0.24 \\
\hline & Group x task & 0.03 & 0.35 & 0.73 & -0.03 & -0.45 & 0.65 & 0.00 & 0.01 & 0.99 & -0.06 & -0.80 & 0.43 \\
\hline \multirow[t]{3}{*}{ Vignettes anger/aggression } & Group & 0.07 & 0.86 & 0.39 & 0.23 & 2.95 & $<0.001^{* *}$ & 0.09 & 1.05 & 0.30 & 0.39 & 5.23 & $<0.001^{* * *}$ \\
\hline & Task & 0.07 & 0.94 & 0.35 & 0.08 & 1.03 & 0.31 & 0.15 & 1.92 & $0.06 \dagger$ & 0.06 & 0.81 & 0.42 \\
\hline & Group x task & 0.12 & 1.57 & 0.11 & 0.02 & 0.28 & 0.78 & 0.12 & 1.56 & 0.12 & 0.09 & 1.18 & 0.24 \\
\hline \multirow[t]{3}{*}{ Vignettes negative } & Group & 0.05 & 0.49 & 0.63 & 0.28 & 2.61 & 0.01 & 0.06 & 0.51 & 0.61 & 0.361 & 3.48 & $<0.001^{* *}$ \\
\hline & Task & 0.10 & 0.87 & 0.39 & -0.10 & -0.87 & 0.39 & 0.03 & 0.29 & 0.78 & 0.049 & 0.45 & 0.65 \\
\hline & Group $\mathrm{x}$ task & 0.15 & 1.60 & 0.11 & -0.11 & -1.17 & 0.25 & 0.08 & 0.83 & 0.41 & 0.002 & 0.02 & 0.98 \\
\hline \multirow[t]{3}{*}{ Vignettes suspicious } & Group & 0.10 & 1.29 & 0.20 & 0.26 & 3.33 & $<0.001^{* *}$ & 0.19 & 2.23 & $0.03^{* \mathrm{a}}$ & 0.409 & 5.11 & $<0.001^{* * *}$ \\
\hline & Task & 0.12 & 1.54 & 0.13 & -0.04 & -0.51 & 0.61 & .19 & 2.15 & $0.03^{*}$ & -0.011 & -0.14 & 0.89 \\
\hline & Group $\mathrm{x}$ task & -0.05 & -0.65 & 0.51 & 0.11 & 1.51 & 0.13 & .06 & 0.69 & 0.49 & -0.023 & -0.29 & 0.77 \\
\hline
\end{tabular}

$* p<0.05 ; * * p<0.01, * * * p<0.001, \dagger<0.1$

a The model predicting TAP reactive aggression with the theme 'suspiciousness' was not significant $\left(\mathrm{F}(3,147)=2.44, p=0.07, R^{2}=0.05\right)$.

Grouped Scatter of RPQ proactive residual by STIAT-effect

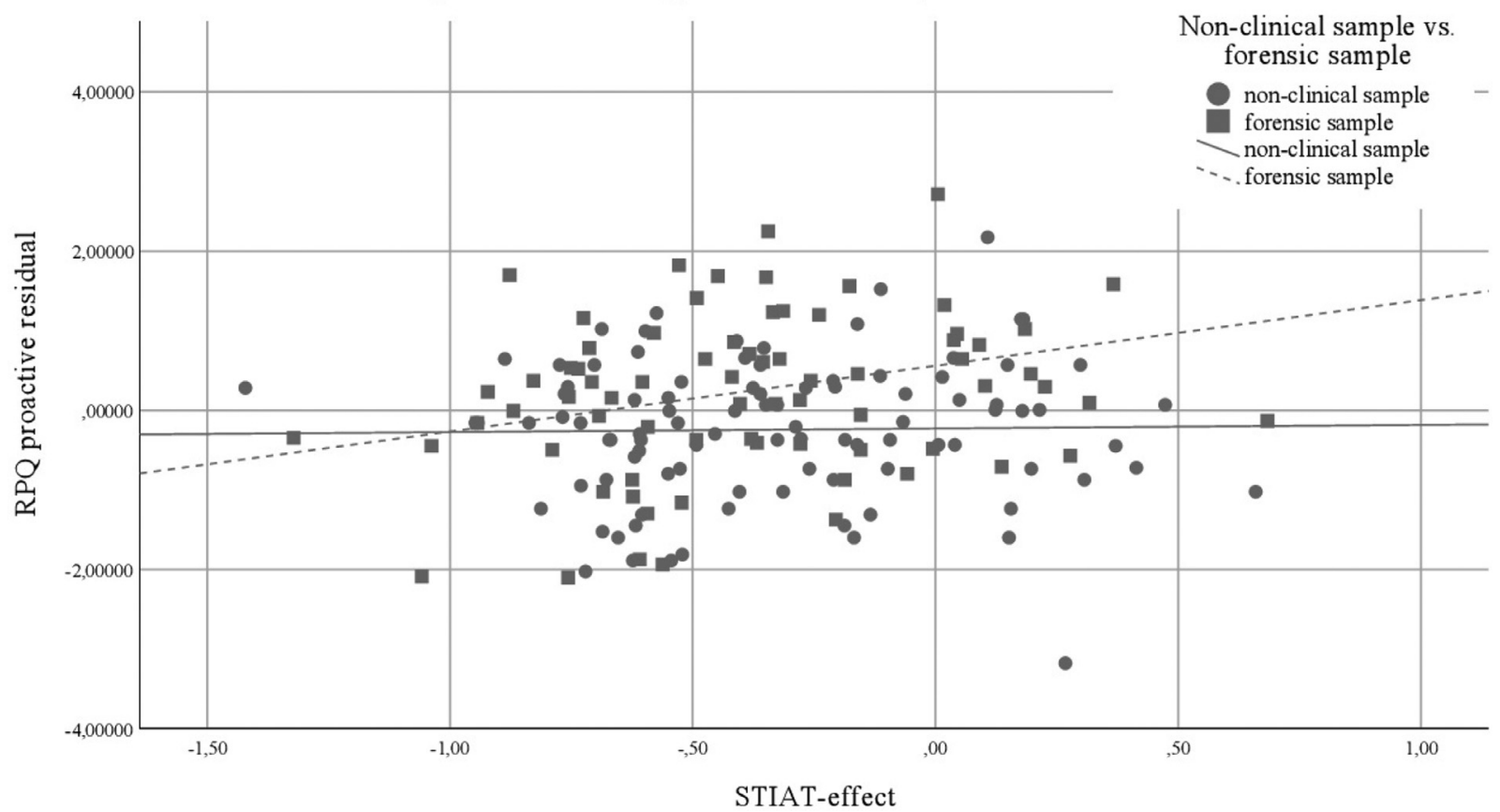

Fig. 1. Grouped scatterplot of RPQ proactive residual by ST-IAT effect.

sentences predicted more reactive aggression $(\beta=0.23, t=2.24$, $p=0.03$ ), whereas the AIBT did not predict TAP reactive aggression in forensic patients $(F(163)=0.72, p=$ n.s. $)$.

\subsubsection{Vignettes}

A significant regression equation was found for the model including the theme 'anger/aggression', group level and the interaction between 'anger/aggression' and group level in predicting reactive aggression $(F$ $(3151)=2.73, p=0.05)$. A borderline significant $p$-value was found for the predictive value of the theme 'anger/aggression' (Table 4); more reports of anger/aggression likely predicts more reactive aggressive behavior. A trend was found for the model predicting TAP reactive 
Grouped Scatter of TAP proactive aggression by aggressive bias on the Emotional Stroop

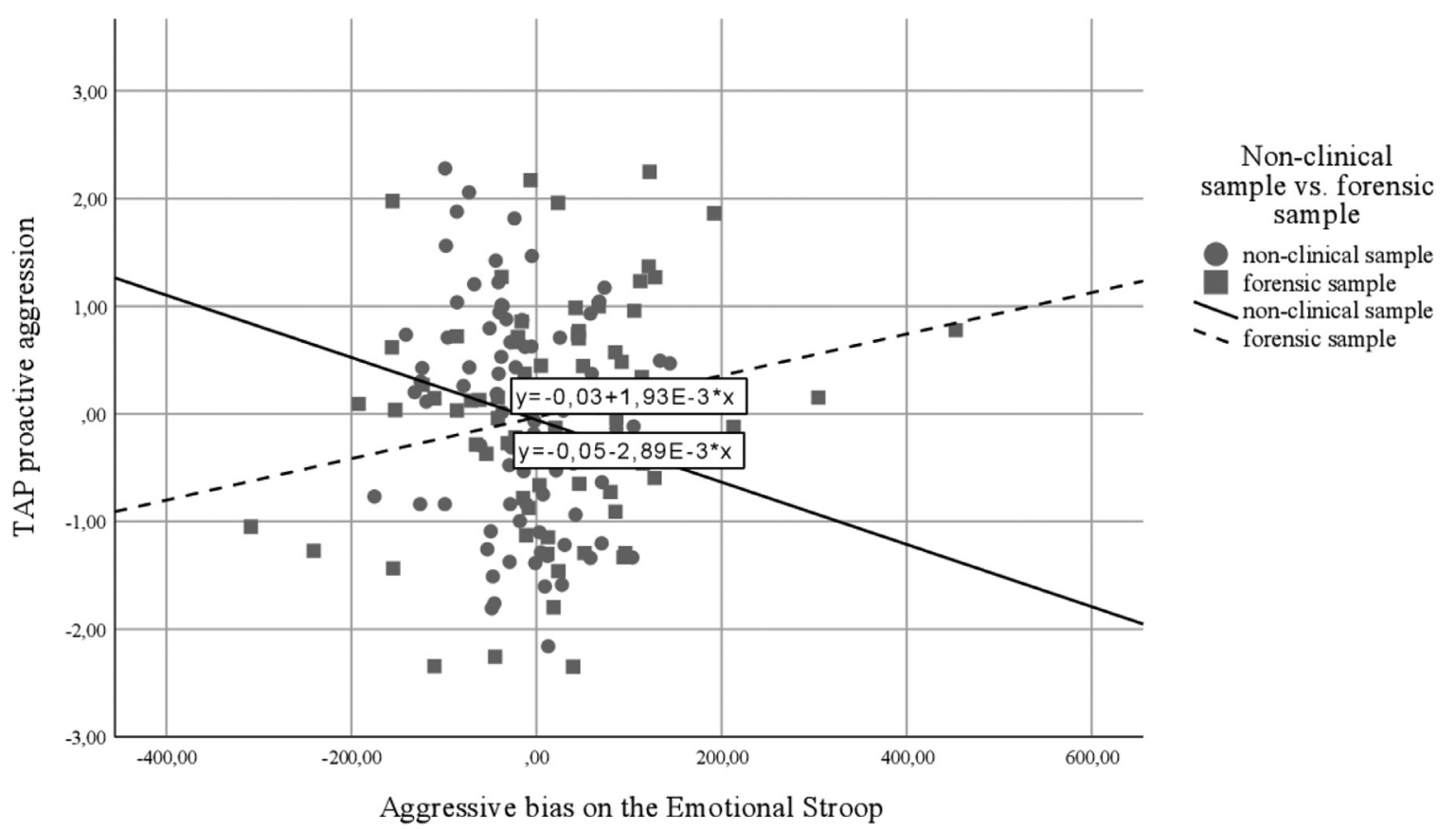

Fig. 2. Grouped scatterplot of TAP proactive aggression by aggressive bias on the emotional stroop.

aggression with the theme 'suspiciousness' $(\mathrm{F}(3147)=2.44, p=0.07$, $\left.R^{2}=0.05\right)$; more reports of suspiciousness likely predicts a higher level of reactive aggressive behavior. The themes 'pain/injury/danger', 'negative', and 'positive' were not significant predictors of TAP reactive aggression. None of the interaction terms were found to be significantly predicting aggression on the TAP. Proactive aggression on the TAP could not be predicted by any of the themes.

\section{Discussion}

We aimed to identify cognitive predictors of reactive and proactive aggression in a forensic psychiatric sample and to compare these with a non-clinical sample. This study showed that some cognitive mechanisms predicted aggressive behavior in both the forensic and the nonclinical sample, whereas others predicted aggressive behavior in only one of the samples. Specifically, an automatic self-aggression association predicted behavioral proactive aggression in both samples.

Grouped Scatter of TAP reactive aggression by AIBT by non-clinical sample vs forensic sample

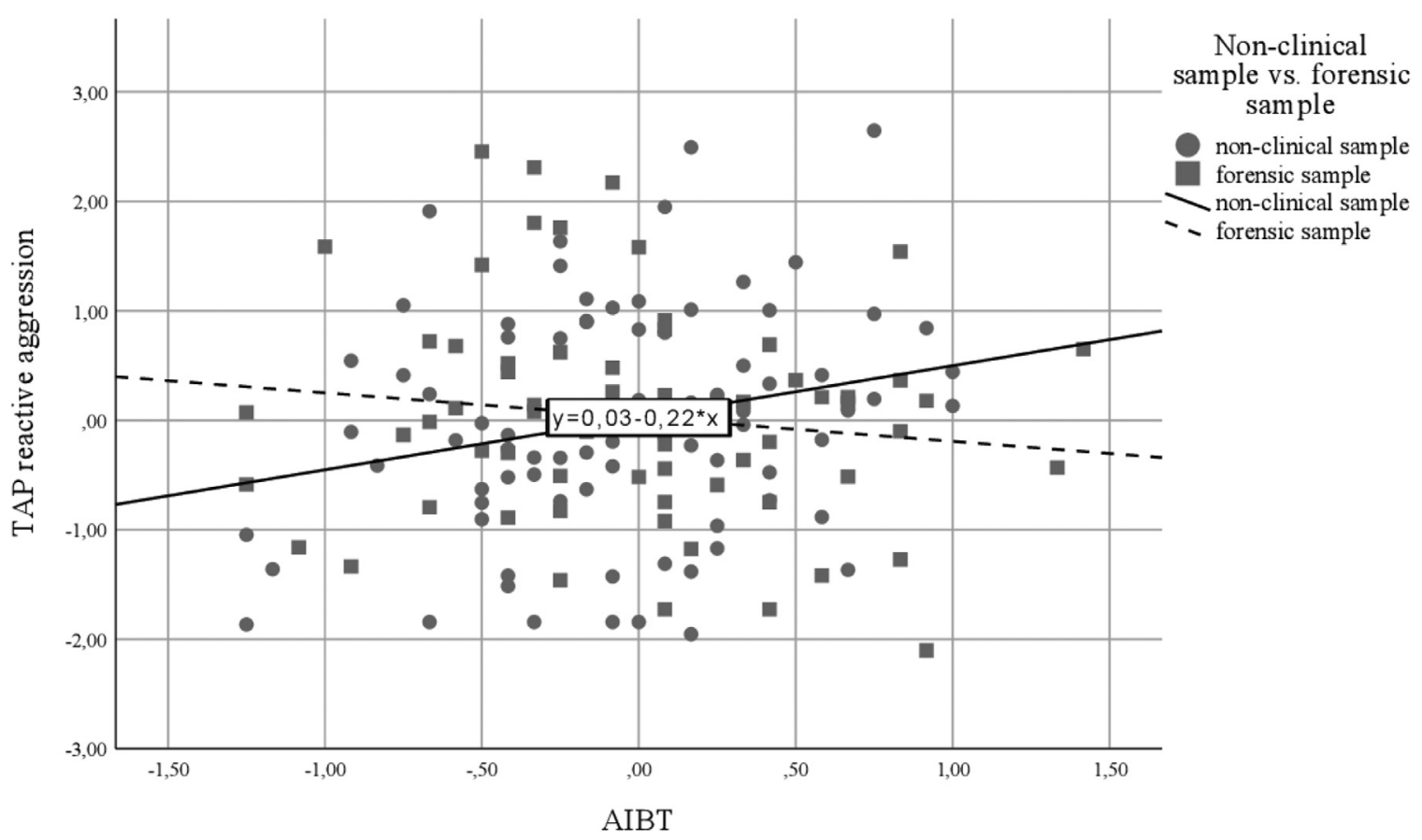

Fig. 3. Grouped scatterplot of TAP reactive aggression by AIBT. 
Study findings in the non-clinical population
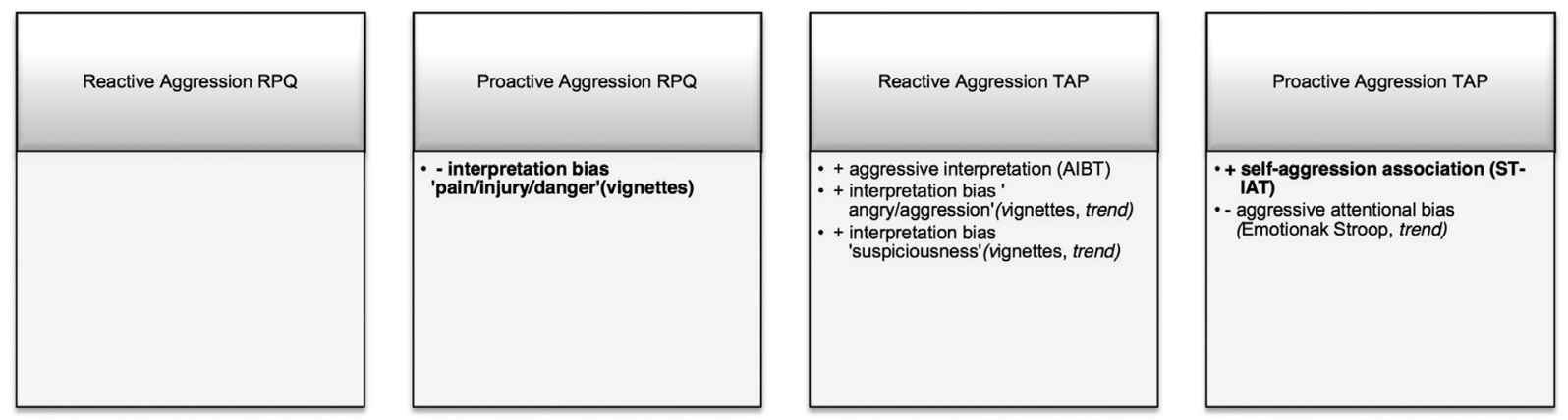

Study findings in the forensic population
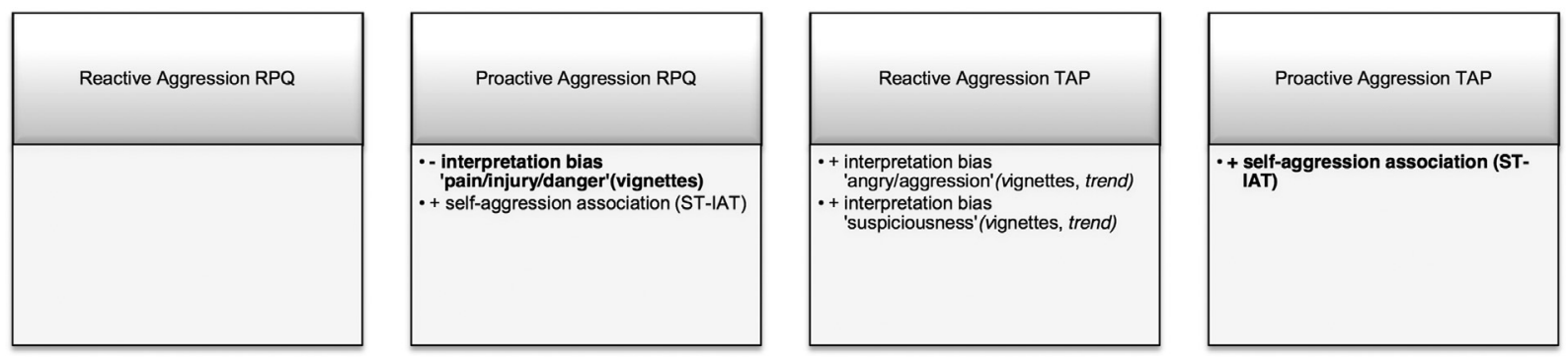

Note: Cognitive predictors that were common for both populations were printed in bold. A+ indicates that an increase of this predictor results in an increase of the level of aggression. $A-$ indicates that a decrease of this predictor results in an increase of the level of aggression.

Fig. 4. Schematic representation of study findings.

Furthermore, higher reports of pain, injuries, or being in danger on the vignette task predicted less self-reported proactive aggression in both samples. In contrast, a stronger aggressive interpretation bias on the AIBT only predicted behavioral reactive aggression in the non-clinical sample. A stronger self-aggression association predicted self-reported proactive aggression in forensic patients only. A schematic presentation of the findings of this study can be found in Fig. 4.

The finding that self-aggression associations predicted behavioral proactive aggression both in the non-clinical sample and the forensic sample is of key importance. It gives insight in the possible mechanism underlying proactive aggression, which proves to be similar for the nonclinical and the forensic sample, thereby suggesting a continuum of a self-aggression association predicting proactive aggression starting from lower levels of proactive aggression in non-clinical samples to high levels in forensic samples. Grumm et al. (2011) already showed that an automatic self-aggression association predicted overall aggressive behavior in children. Richetin et al. (2010) showed that after provocation, an automatic self-aggression association predicted (selfreported) reactive aggression. Our previous study (Brugman et al., 2015) evidenced such a predictive value of an automatic self-association for behavioral proactive aggression, which could reflect the more trait-like nature of proactive aggression. Proactive aggression does not need to be primed or provoked in order to be measured in an implicit manner. In contrast, automatic self-aggression associations can by definition only be predictive of reactive aggression after provocation, as reactive aggression needs a trigger. The question remains whether an automatic self-aggression association is related to the fourth step of the SIP-model (response accessibility in memory) or whether it merely reflects an increased overall trait-like, aggressive predisposition. Interestingly, self-reported proactive aggression was predicted by an automatic self-aggression association in the forensic sample only. These patients are in forensic treatment facilities because of their aggressive behavior. Therefore, it is possible that patients are (or, due to treatment, became) more aware of their individual level of trait-like (proactive) aggressive behavior and, therefore, show a stronger relationship between level of self-aggression association on the ST-IAT and level of self-reported proactive aggressive on the RPQ. Another possible explanation for the finding that the ST-IAT only predicted selfreported aggression in the forensic sample is that there is a difference in variance between groups on self-aggression association. This idea was tested with a non-parametric Levene's test, which indicated equal variances between groups on the reaction times on block 3 and block 5 of the ST-IAT. This means that the finding that the ST-IAT only predicts self-reported proactive aggression in the forensic sample only is not due to differences in variances between groups.

In both samples, pain/injury/danger interpretations predicted less proactive aggression on the RPQ. While there are no previous studies directly comparing the relation between proactive aggression and these interpretations in ambiguous situations, indirect support for our findings can be derived from studies hinting towards a relation between a decreased sensitivity for pain and proactive aggression. This relation is specifically found in studies on psychopathic traits (e.g. Miller et al., 2014; Brislin et al., 2016). Psychopathy has been related to high levels of proactive aggression (e.g. Cima and Raine, 2009). A study of Miller et al. (2014), for example showed that individuals with psychopathic traits have an increased tolerance for pain, which was also related to a history of antisocial and aggressive behavior.

In contrast to our expectations, no predictive value was found of the Emotional Stroop in the forensic sample. Instead, a trend was found towards a relation between a stronger attentional interference of aggressive stimuli and proactive aggressive behavior on the TAP in nonforensic participants only. We could not replicate (Brugman et al., 2015) the predictive value of the Emotional Stroop for reactive aggression on the TAP in the non-forensic sample either. A first possible explanation is that the trend for the predictive value of an attentional bias towards aggressive stimuli in predicting behavioral proactive aggression in a non-clinical sample only indicates that this 'attentional distortion - proactive aggression link' works truly qualitatively different 
in a forensic sample. A second possible explanation is that the results on predictive validity of the Emotional Stroop are unstable and depend on the other factors entered into the analyses. In the study of Brugman et al. (2015) the predictive value of the Emotional Stroop was examined together with the ST-IAT. The third possible explanation is that there is significant difference between groups regarding variance on the Emotional Stroop. This idea was tested with a non-parametric Levene's test, which indicated unequal variances for the reaction times on each block (Neu: $\mathrm{F}=136.88, p<0.001$; Neg: $F=111.30$, $p<0.001$; Agg: $F=121.45, p<0.001$; Pos: $F=108.30, p<0.001$ ). The forensic sample showed more variance on the Emotional Stroop variables than the non-clinical sample. One would expect that the predictive value of the Emotional Stroop would be higher in the sample showing more variance (in this case the forensic sample) than in sample with lower variance (the non-clinical sample), however this was not the case in this study. Thus, it is likely that the finding that the Emotional Stroop predicts aggression in the non-clinical sample only is due to factors other than the difference in variance on the Emotional Stroop variables.

No predictive value was found for the AIBT in the forensic sample, while this task did predict reactive aggression on the TAP in the nonclinical sample. Forensic patients might not have an aggressive interpretative bias predictive of behavioral reactive aggression. As the vignette task did have some predictive value (for the theme 'pain/injury/danger' and possibly also 'anger/aggression' and 'suspiciousness'), predictive value of measuring an interpretation bias to predict aggressive behavior in the forensic sample might still exist. However, the AIBT might not be the best task to measure an interpretation bias in this sample, leading to a lack of predictive value. As the samples differ in educational level, the AIBT could be more (or too) challenging for forensic patients. Moreover, as can be seen in Table 2, the reliability of the AIBT is rather low, indicating that the results on this task need to be interpreted with caution. This could also account for the difference in predictive value between groups for this task.

Finally, in all models predicting self-reported as well as behavioral proactive aggression, forensic patients showed significantly more proactive aggression compared to the non-clinical sample. This was not the case for the models of reactive aggression. Note that in our regression models, the standardized residual scores of reactive and proactive aggression were used and, for the TAP, an orthogonal rotation was used to be able to examine the predictive value of the cognitive tasks on the unique aspects of reactive and proactive aggression. Our findings, thus, imply that the non-clinical and forensic samples do not significantly differ from one another on the unique aspects of reactive aggression, while they do on the unique aspects of proactive aggression. Proactive aggression, therefore, is likely a distinct characteristic of the forensic samples.

To conclude, it seems that reactive and proactive aggression cannot simply be predicted by the same mechanisms in both non-clinical and forensic samples. Only automatic self-aggression association can be considered a common predictor of proactive aggression on the TAP. Next to this, giving answers related to pain, injuries, or being in danger on the vignette task predicted less self-reported proactive aggression in both samples. Thus, a self-aggression association and an interpretation bias of the theme pain/injury/danger may reflect mechanisms linearly predicting aggressive behavior in both non-clinical and forensic participants.

Similar results were found in a review of Upthegrove et al. (2016), who examined the mechanisms underlying auditory verbal hallucinations (AVH's). AVH's occur often in patients with schizophrenia and other psychotic disorders, but can also occur in normal samples. Dimensional models, therefore, propose that AVH's lie on a continuum from normal to abnormal experience. Although some similar brain processes were involved in AVH's in both non-clinical and clinical samples, the authors stress the importance to also consider the unique mechanisms underlying AVH's in clinical samples and re-examine the dimensional continuum approach of AVH's.

An alternative theory is that the aggressive behavior we are trying to predict is not linear, but rather dynamic or 'chaotic' . The Dynamic Systems Theory (Thelen and Smith, 2007) is a statistical approach to explain behavior by using equations. To date, there are already some studies on aggressive behavior and antisocial behavior using this theory (e.g. Granic and Patterson, 2006; Burge et al., 2016, Caprara et al., 2007). Burge et al. (2016) for example indicate that the most common pattern in partner violence is random, which challenges the predictability and treatability of the behavior. Caprara et al. (2007) indicate that about $25 \%$ of initially marginally deviant children become seriously aggressive adolescents (i.e. from minor deviations to disorder) over time through dynamic processes (i.e. non-linear shifts). Together with our findings, these studies clarify that we need to be cautious assuming that the cognitive mechanisms underlying aggression in nonclinical and clinical samples lie on a continuum.

\subsection{Strengths and limitations}

Our study is unique in many respects. To our best knowledge, we are the first to directly compare a non-clinical and a clinical sample, thus being able to test whether or not the same cognitive processes related to aggression play a role in non-patients and forensic patients. Furthermore, the predictive value of multiple steps of the SIP-model was examined in this work by using a variety of cognitive tasks. Moreover, implicit cognitive tasks and a behavioral measure of aggressive behavior were used, which is of key importance in a forensic sample, where lack of insight and social desirable responding is a problem (e.g. Scheier et al., 1978).

The inclusion of male participants limits the generalization of the conclusions to females. Another limitation of this study is that in the forensic sample we did not select patients based upon any aggressive predisposition or upon index offence. It was decided to not select, as we were interested in aggressive behavior as a dimensional construct. This decision resulted in a heterogeneous forensic sample, including patients with different types of personality disorders and a number of patients with a sexual disorder. The relation between aggression and sexual disorders is quite a complex one. There are sexual disorders in which the occurrence of aggression is quite clear (e.g. sadism and sexual masochism) and sexual disorders in which it is less clear (e.g.pedophilia; Revitch \& Weiss, 1962; Marshall \& Christie, 1981). Altogether, we did expect a relative high level of aggression in the forensic sample, considering the amount of patients with an antisocial personality disorder or traits of this disorder and the number of patients with a high PCL-R score. A final limitation is that no statements can be made about the causal relations between the cognitive mechanisms studied here and aggressive behavior. We do not suggest that any of these cognitive mechanisms cause aggressive behavior. In this study, only conclusions about the predictive value of these mechanisms were made. It would be interesting to examine the causal relation between these cognitions and aggression in the future.

\subsection{Implications}

A stronger implicit self-aggression association turned out to be a predictor for both self-reported and behavioral proactive aggression in forensic patients. It would be interesting to see whether this implicit association is also predictive of in-clinic aggressive incidents and violent recidivism. If so, then it would be recommendable to test whether the ST-IAT has incremental explanatory value to currently used risk taxation instruments (e.g. Historical-Clinical-Risk Management-20 or HCR-20V3; Douglas et al., 2014). Furthermore, the results show that biased interpretations of ambiguous information predicted aggressive behavior, which emphasizes the importance to focus on these maladaptive interpretation strategies in therapy. Focusing on maladaptive interpretation strategies is also a key goal of cognitive behavioral 
therapy, which has proven to have positive effects on recidivism in criminal offenders (Lipsey et al., 2007). In Responsive Aggression Regulation Therapy, a module of on interpretation strategies is also included and this therapy has been shown to be more effective than TAU (treatment-as-usual) in a group of juvenile offenders on recidivism risk, aggressive behavior, and cognitive distortions (Hoogsteder et al., 2014). More research on the effectiveness of this type of therapy on adult offenders is needed in the future.

\section{Acknowledgments}

We thank the Laboratory of Social Psychology at Florida State University for sharing their TAP with us. We thank Vivian van den Boomen, Rachel van den Akker, Renée van Dommelen, Danielle Pessers, Anne van den Kieboom, Hannah van Meel, Shita van den Booren and Danitsja Heijligers for their help during this project. Finally, we would like to thank the Pompekliniek, Nijmegen, de Rooyse Wissel, Oostrum, and GGZ Breburg for their cooperation in this study.,

\section{Funding}

This work was supported by a grant from the Netherlands Organization for Scientific Research (NWO; HCMI 10-19).

\section{Supplementary materials}

Supplementary material associated with this article can be found, in the online version, at doi:10.1016/j.psychres.2018.08.095.

\section{References}

Anderson, C.A., Bushman, B.J., 2002. Human aggression. Annu. Rev. Psychol. 53, 27-51. https://doi.org/10.1146/annurev.psych.53.100901.135231.

Archer, J., 2004. Sex differences in aggression in real-world settings: a meta-analytic review. Rev. Gen. Psychol. 8, 291-322. https://doi.org/10.1037/1089-2680.8.4.291.

Banse, R., Messer, M., Fischer, I., 2015. Predicting aggressive behavior with the aggressiveness-IAT. Aggress. Behav. 41, 65-83. https://doi.org/10.1002/ab.21574.

Barnett, V., Lewis, T., 1978. Outliers in Statistical Data. John Wiley, Chichester. https:// doi.org/10.2307/2066277.

Brislin, S.J., Buchman-Schmitt, J.M., Joiner, T.E., Patrick, C.J., 2016. "Do unto others"? Distinct psychopathy facets predict reduced perception and tolerance of pain. Personal. Disord. 7, 240-246. https://doi.org/10.1037/per0000180.

Brugman, S., Lobbestael, J., Arntz, A., Cima, M., Schuhmann, T., Dambacher, F., et al. 2015. Identifying cognitive predictors of reactive and proactive aggression. Aggress. Behav. 41, 51-64. https://doi.org/10.1002/ab.21573.

Brugman, S., Lobbestael, J., von Borries, A.K.L., Bulten, B.E.H., Cima, M., Schuhmann, T., et al., 2016. Cognitive predictors of violent incidents in forensic psychiatric inpatients. Psychiatry Res. 237, 229-237. https://doi.org/10.1016/j.psychres.2016.01. 035.

Burge, S.K., Katerndahl, D.A., Wood, R.C., Becho, J., Ferrer, R.L., Talamantes, M., 2016. Using complexity science to examine three dynamic patterns of intimate partner violence. Fam. Syst. Health 34, 4-14. https://doi.org/10.1037/fsh0000170.

Caprara, G.V., Dodge, K.a, Pastorelli, C., Zelli, A., 2007. How marginal deviations sometimes grow into serious aggression. Child Dev. Perspect. 1, 33-39. https://doi. org/10.1111/j.1750-8606.2007.00007.x.

Cima, M., Raine, A., 2009. Distinct characteristics of psychopathy relate to different subtypes of aggression. Pers. Individ. Dif. 47, 835-840. https://doi.org/10.1016/j. paid.2009.06.031.

Cima, M., Raine, A., Meesters, C., Popma, A., 2013. Validation of the Dutch Reactive Proactive Questionnaire (RPQ): differential correlates of reactive and proactive aggression from childhood to adulthood. Aggress. Behav. 39, 99-113. https://doi.org/ 10.1002/ab.21458.

Cohen, D.J., Eckhardt, C.I., Schagat, Klaus,D., 1998. Attention allocation and habituation to anger-related stimuli during a visual search task. Agoress. Behav. 24, 399-409.

Crick, N.R., Dodge, K.A., 1996. Social information-processing mechanisms in reactive and proactive aggression. Child Dev. 67, 993-1002. https://doi.org/10.1111/j.14678624.1996.tb01778.x.
Crick, N.R., Dodge, K.A., 1994. A review and reformulation of social information-processing mechanisms in children's social adjustment. Psychol. Bull. 115, 74-101. https://doi.org/10.1037/0033-2909.115.1.74.

de Castro, B.O., Veerman, J.W., Koops, W., Bosch, J.D., Monshouwer, H.J., 2002. Hostile attribution of intent and aggressive behavior: a meta-analysis. Child Dev. 73, 916-934. https://doi.org/10.1111/1467-8624.00447.

Douglas, K.S., Hart, S.D., Webster, C.D., Belfrage, H., Guy, L.S., Wilson, C.M., Management-, C.M.W.H., 2014. Historical-Clinical-Risk Management-20, Version 3 (HCR-20): Development and Overview Historical-Clinical-Risk Management-20, Version 3 (HCR-20 V3): Development and Overview. Int. J. Forensic Ment. Health 13 93-108. https://doi.org/10.1080/14999013.2014.906519.

Granic, I., Patterson, G.R., 2006. Toward a comprehensive model of antisocial development: a dynamic systems approach. Psychol. Rev. 113, 101-131. https://doi.org/10. 1037/0033-295X.113.1.101.

Grumm, M., Hein, S., Fingerle, M., 2011. Predicting aggressive behavior in children with the help of measures of implicit and explicit aggression. Int. J. Behav. Dev. 35, 352-357. https://doi.org/10.1177/0165025411405955.

Hare, R.D., 1991. The Hare Psychopathy Checklist - Revised. Multihealth Systems, Toronto. https://doi.org/10.1037/t01167-000.

Van Honk, J., Tuiten, A., Van Den Hout, M., Putman, P., De Haan, E., Stam, H., 2001. Selective attention to unmasked and masked threatening words: relationships to trait anger and anxiety. Pers. Individ. Dif. 30, 711-720. https://doi.org/10.1016/S01918869(00)00160-4.

Hoogsteder, L.M., Kuijpers, N., Stams, G.J.J.M., van Horn, J.E., Hendriks, J., Wissink, I.B., 2014. Study on the effectiveness of Responsive Aggression Regulation Therapy (ReART). Int. J. Forensic Ment. Health 13, 25-35. https://doi.org/10.1080/14999013. 2014.893711.

Karpinski, A., Steinman, R.B., 2006. The single category implicit association test as a measure of implicit social cognition. J. Pers. Soc. Psychol. 91, 16-32. https://doi.org/ 10.1037/0022-3514.91.1.16.

Kirsh, S.J., Olczak, P.V., Mounts, J.R.W., 2005. Violent video games induce an affect processing bias. Media Psychol. 7, 239-250. https://doi.org/10.1207/ S1532785XMEP0703_1.

Lipsey, M.W., Landerberger, N.A., Wilson, S.J., 2007. Effects of cognitive-behavioural programs for criminal offenders. Campbell Syst. Rev. 6, 1-27. https://doi.org/10. 4073/csr.2007.6.

Lobbestael, J., Cima, M., Arntz, A., 2013. The relationship between adult reactive and proactive aggression, hostile interpretation bias, and antisocial personality disorder. Journal of Personality Disorders 27 (1), 53-56.

Marshall, W.L., Christie, M.M., 1981. Pedophilia and Aggression. Crim. Justice Behav. 8, 145-158. https://doi.org/10.1177/009385488100800202.

Miller, J.D., Rausher, S., Hyatt, C.S., Maples, J., Zeichner, A., 2014. Examining the relations among pain tolerance, psychopathic traits, and violent and nonviolent antisocial behavior. J. Abnorm. Psychol. 123, 205-213. https://doi.org/10.1037/ a0035072.

Parrott, A. C. (1991). Performance tests in human psychopharmacology (1): Test reliability and standardization. Human Psychopharmacology: Clinical and Experimental. https://doi.org/10.1002/hup.470060102.

Raine, A., Dodge, K., Loeber, R., Gatzke-Kopp, L., Lynam, D., Reynolds, C., StouthamerLoeber, M., et al., 2006. The reactive-proactive aggression questionnaire: differential correlates of reactive and proactive aggression in adolescent boys. Aggress. Behav. 32, 159-171. https://doi.org/10.1002/ab.20115.

Revitch, E., Weiss, R.G., 1962. The pedophiliac offender. Dis. Nerv. Syst. 23, 73-78.

Richetin, J., Richardson, D.S., Mason, G.D., 2010. Predictive validity of IAT aggressiveness in the context of provocation. Soc. Psychol. (Gott). 41, 27-34. https://doi.org/ 10.1027/1864-9335/a000005.

Scheier, M.F., Buss, A.H., Buss, D.M., 1978. Self-consciousness, self-report of aggressiveness, and aggression. J. Res. Pers. 12, 133-140. https://doi.org/10.1016/00926566(78)90089-2.

Schmand, B., Bakker, D., Saan, R., Louman, J., 1991. [The Dutch reading test for adults: a measure of premorbid intelligence level]. Tijdschr. Gerontol. Geriatr. 22, 15-19.

Stewart, J.L., Silton, R.L., Sass, S.M., Fisher, J.E., Edgar, J.C., Heller, W., et al., 2010. Attentional bias to negative emotion as a function of approach and withdrawal anger styles: an ERP investigation. Int. J. Psychophysiol. 76, 9-18. https://doi.org/10. 1016/j.ijpsycho.2010.01.008.

Strack, F., Deutsch, R., 2004. Reflective and impulsive determinants of social behavior. Personal. Soc. Psychol. Rev. 8, 220-247. https://doi.org/10.1207/ s15327957pspr0803 1.

Taylor, S.P., 1967. Aggressive behavior and physiological arousal as a function of provocation and the tendency to inhibit aggression. J. Pers. 35, 297-310. https://doi. org/10.1111/j.1467-6494.1967.tb01430.x.

Thelen, E., Smith, L.B., 2007. Dynamic systems theories. Handbook of Child Psychology. . https://doi.org/10.1002/9780470147658.chpsy0106.

Upthegrove, R., Broome, M.R., Caldwell, K., Ives, J., Oyebode, F., Wood, S.J., 2016. Understanding auditory verbal hallucinations: a systematic review of current evidence. Acta Psychiatr. Scand. https://doi.org/10.1111/acps.12531. 